\title{
Production of 2,3-butanediol from cellulose and Jatropha hulls after ionic liquid pretreatment and dilute-acid hydrolysis
}

\author{
Li-qun Jiang ${ }^{1,2}$, Zhen Fang ${ }^{1 *}$, Xing-Kang Li ${ }^{1,2}$ and Jia Luo ${ }^{1}$
}

\begin{abstract}
Abundant Jatropha waste is a promising renewable feedstock for the production of sugars and 2,3-butanediol fermentation. To obtain high yield of water-soluble products and high concentration of reducing-sugars, ionic liquid (IL) pretreatment and dilute acid hydrolysis at $150^{\circ} \mathrm{C}$ were combined in this work. The destruction of crystalline structure and increase surface area of biomasses after IL-pretreatment, made their hydrolysis more efficient. Compared with original cellulose, after IL-pretreatment, both the yield and concentration of reducing-sugars increased by $139 \%$, and the water-soluble products yield increased by $128 \%$ after hydrolysis. Compared with water-washed Jatropha hulls, after IL-pretreatment, the yield and concentration of reducing-sugars increased by $80 \%$ and $76 \%$, respectively, and the water-soluble products yield increased by $70 \%$ after hydrolysis. IL-pretreatment benefited the fermentation of Jatropha hull hydrolysate with $66.58 \%$ diol yield and its productivity increased from 0.35 to $0.40 \mathrm{~g} /(\mathrm{L} \cdot \mathrm{h})$.
\end{abstract}

Keywords: Ionic liquid; Hydrolysis; 2,3-Butanediol; Fermentation; Klebsiella oxytoca; Jatropha hulls

\section{Introduction}

2,3-Butanediol is a promising liquid fuel and bulk chemical for comprehensive industry applications (Garg and Jain 1995; Syu 2001). Biological production of 2,3-butanediol on an industrial-scale is still in its early stage but with strong prospects of growth. However, the substrates account for more than half of the total production cost, and strongly influence the economy of its production (Celińska and Grajek 2009; Wang et al. 2010; Ji et al. 2011). As the most abundant, cheap and renewable source of sugars substrate, lignocellulose is a promising feedstock for biorefinery. Jatropha hulls are wastes from Jatropha seeds for biodiesel synthesis. One tonne of Jatropha seeds provides about 350-L crude oil for biodiesel production leaving 2.4 tonne hulls as waste (Sharma et al. 2009). As Jatropha hulls are rich in carbohydrates, studies are required to efficiently utilize these polysaccharides to produce sugars for fermentation.

\footnotetext{
* Correspondence: zhenfang@xtbg.ac.cn

'Biomass Group, Laboratory of Tropical Plant Resource Science, Xishuangbanna Tropical Botanical Garden, Chinese Academy of Sciences, 88 Xuefulu, Kunming, Yunnan Province 650223, China

Full list of author information is available at the end of the article
}

Fermentable sugars can be produced by pretreatment and subsequent enzymatic hydrolysis. In previous study (Marasabessy et al. 2012), a dilute acid pretreatment of Jatropha hulls at optimum conditions $(0.9 \%$ sulfuric acid, $30 \mathrm{~min}, 178^{\circ} \mathrm{C}$ ) for enzymatic hydrolysis and ethanol fermentation resulted in $29 \%$ pentose degradation into furfural and 5\% hexose degradation into 5-hydroxymethylfurfural (5-HMF). The degradation of sugars could not only result in low yield and high cost of sugars derived from biomass, but also lead to the formation of toxic by-products for fermentation. In addition, slow hydrolysis rate, high cost of enzyme and sensitivity to contaminants originated from other biomass components restrict its economical feasibility (Brinder et al. 2010). Two-step dilute sulfuric acid hydrolysis was used to effectively hydrolyze Jatropha hulls at $150^{\circ} \mathrm{C}$ for 2,3-butanediol fermentation in our previous work (Jiang et al. 2012). Hemicellulose and amorphous cellulose of Jatropha hulls can be easily hydrolyzed without any pretreatment but crystalline cellulose is more difficult to be hydrolyzed, thus harsh conditions are needed for it. However, severe conditions also accelerate the secondary 
decomposition of sugars. In addition, low concentration of fermentable sugars in the hydrolysate is one of the critical issues in the utilization of lignocellulose for biofuels and bio-based chemicals production. Cellulose crystallinity is a negative factor that affects biomass hydrolysis. Ionic liquids (ILs) have excellent properties to treat lignocellulose and make the crystallinity remarkable decrease and structure essentially amorphous and porous for efficient hydrolysis (Tian et al. 2011; Li et al. 2013). ILs are recyclable and IL-pretreatment is considered as an environmentally-friendly alternative to conventional pretreatment methods (Liu et al. 2012; Shafiei et al. 2013). As IL-pretreatment can effectively decrystallize cellulose, both hemicellulose and cellulose components can be hydrolyzed simultaneously at relatively moderate conditions after IL-pretreated. This strategy seems a promising route to make full utilization of raw material and achieve high concentration of sugars in the hydrolysate of Jatropha hulls.

In this study, the feasibility of combination of ILpretreatment with dilute acid-hydrolysis of Jatropha hulls for fermentable sugars to produce 2,3-butanediol was evaluated. Microcrystalline cellulose and Jatropha hulls were pretreated by IL1-butyl-3-methylimidazoliuma chloride ([BMIM]Cl) before their subsequent dilute sulfuric acid hydrolysis. Untreated cellulose and water-washed Jatropha hulls were employed as control samples for comparison. The hydrolysates were further fermented to 2,3-butanediol with Klebsiella oxytoca.

\section{Materials and methods Material}

Original Jatropha hulls (OJH) were obtained from Xishuangbanna Tropical Botanical Garden in Yunnan, China. They were air-dried at $70^{\circ} \mathrm{C}$ for $24 \mathrm{~h}$, milled then passed through 80-150 meshes. Structural carbohydrates and lignin in Jatropha hulls were determined according to the National Renewable Energy Laboratory (NREL) procedure (Sluiter et al. 2008). The elemental composition of Jatropha hulls were analyzed by an organic elemental analyzer (Vario EL III, Hanau, Germany). Microcrystalline cellulose (Cat. No. 6288) was purchased from Sigma (Shanghai), milled to the size of less than 150 meshes and dried in an oven at $60^{\circ} \mathrm{C}$ for $24 \mathrm{~h}$ before use. [BMIM]Cl (purity 99\%) was from Lanzhou Institute of Chemical Physics, Chinese Academy of Sciences (Lanzhou, China). The strain used for 2,3-butanediol production was Klebsiella oxytoca (CICC 22912) from China Center of Industrial Culture Collection (Beijing).

\section{IL-pretreatment}

Biomass suspension in IL[BMIM]Cl was prepared by adding 4-g (4 wt\%) cellulose or $\mathrm{OJH}$ in a $500-\mathrm{mL}$ flask containing 100-g IL. Then, without removing air, the flask was sealed with a cork and placed in oil bath at $120^{\circ} \mathrm{C}$ with stirring at $400 \mathrm{rpm}$ for $1 \mathrm{~h}$. Deionized water at $90^{\circ} \mathrm{C}(400-\mathrm{mL})$ was added to the mixture to precipitate biomass with vigorous shaking for $10 \mathrm{~s}$. The regenerated biomass was then transferred into a 1000-mL beaker with deionized water at $75^{\circ} \mathrm{C}$, washed with $75^{\circ} \mathrm{C}$ water (700-mL) thoroughly for 15 times to remove IL, freeze-dried (EYELA 1200 freeze dryer, Tokyo Rikakikai Co., Ltd.) and recovered as ILpretreated cellulose (ILC) or IL-pretreated Jatropha hulls (ILJH). The recovered biomass was weighted and used for sulfuric acid hydrolysis. OJH powders were also washed with $700-\mathrm{mL}$ fresh deionized water at $75^{\circ} \mathrm{C}$ for 15 times, freeze-dried, and recovered as water-washed Jatropha hulls (WJH). Recovery rate of regenerated biomass was calculated using the following equation:

$$
\begin{aligned}
& \text { Recovery rate of regenerated biomass }(\mathrm{wt} \%) \\
& =(\text { Mass of regeneraged biomass }) \\
& \quad \div(\text { Mass of initial biomass }) \times 100 \%
\end{aligned}
$$

\section{Crystallinity measurement}

Crystallinity index (CrI) of samples was determined by X-ray diffraction (XRD) in a Rigaku TTR III X-ray diffractmeter (Tokyo). X-ray diffractometer was set at $40 \mathrm{kV}$ and $200 \mathrm{~mA}$. Cu radiation $(\lambda=1.54 \AA)$ was scanned over diffraction angle $\left(2 \theta^{\circ}\right)$ of $5-50^{\circ}$ with a step of $0.01^{\circ}$. CrI was determined by the equation (Segal et al. 1959):

$$
\operatorname{CrI}(\%)=\left(\mathrm{I}_{002}-\mathrm{I}_{\mathrm{am}}\right) / \mathrm{I}_{002} \times 100 \%
$$

where $\mathrm{I}_{002}$ was the highest peak intensity at an angle of diffraction of $2 \theta=22.5^{\circ}$, whereas $I_{a m}$ was the peak for the amorphous cellulose at $2 \theta=18^{\circ}$.

\section{Measurement of specific surface area}

Specific surface area of samples was determined by Bruner Emmett and Teller (BET) method (Tristar II 3020, Micromeritics Instrument Co., Ltd, Northcross, GA). Samples were degassed at $100^{\circ} \mathrm{C}$ for $3 \mathrm{~h}$ and nitrogen with relative pressure of $0.05-0.985$ was applied in the analyses.

\section{Dilute sulfuric acid hydrolysis}

The acid hydrolysis reaction was carried out in a 500-mL high pressure autoclave (FCFD05-30, Yantai Jianbang Chemical Mechanical Co. Ltd., Shandong, China). For hydrolysis of Jatropha hulls, 15-g WJH or ILJH powders were loaded in the autoclave containing 200-mL $1.5 \mathrm{wt} \%$ dilute sulfuric acid solution, and reacted at $150^{\circ} \mathrm{C}$ for $0.5 \mathrm{~h}$. For hydrolysis of cellulose, $9 \mathrm{~g}$ or $15 \mathrm{~g}$ untreated cellulose or ILC powders were loaded in the autoclave with 200-mL 4 wt\% dilute sulfuric acid, and reacted at 
$150^{\circ} \mathrm{C}$ for $1 \mathrm{~h}$. Concentrations of furfural and 5-HMF were analyzed by high performance liquid chromatography (HPLC, LC-20A, Shimadzu, Tokyo) fitted with a refractive index detector and Aminex HPX-87H column (Bio-Rad, Hercules, CA) at $60^{\circ} \mathrm{C}$ with $0.005 \mathrm{M} \mathrm{H}_{2} \mathrm{SO}_{4}$ as mobile phase at a flow rate of $0.6 \mathrm{~mL} / \mathrm{min}$. The carbon amount in the aqueous phase was determined by total organic carbon (TOC) analyzer (TOC-5000A, Shimadzu). Concentration of reducing-sugars in hydrolysate solutions was measured by 3,5-dinitrosalicylic acid (DNS) method using an ultraviolet-visible (UV-Vis) spectrophotometer (UV 1800, Shimadzu) (Miller 1959). The yield of watersoluble products and the yield of reducing-sugars were calculated as follows:

$$
\begin{aligned}
& \text { Reducing-sugars yield }(\text { wt } \%) \\
& =\text { ( Mass of reducing-sugars }) \\
& \quad \div(\text { Mass of cellulose }+ \text { Mass of hemicellulose }) \\
& \quad \times 100 \%
\end{aligned}
$$

$$
\begin{aligned}
& \text { Water-soluble products yield }(\mathrm{wt} \%) \\
& \begin{array}{l}
=(\text { Carbon mass of water-soluble organic compounds }) \\
\quad \div(\text { Carbon mass of biomass }) \times 100 \%
\end{array}
\end{aligned}
$$

The hydrolysates were neutralized with calcium hydroxide to $\mathrm{pH} 7.0$ and concentrated under vacuum at $60-70^{\circ} \mathrm{C}$ to achieve approximately $100 \mathrm{~g} / \mathrm{L}$ sugar concentration. The concentrated hydrolysate solutions $(100 \mathrm{~mL})$ were detoxicated in a $250-\mathrm{mL}$ flask containing 2-g activated charcoal (Baoman Biochemical Co. Ltd., Shanghai). The flask was placed in a shaker at $50^{\circ} \mathrm{C}$ and $200 \mathrm{rpm}$ for $2 \mathrm{~h}$. Finally, after removing the charcoal by filtration, the solutions were ready for fermentation.

\section{Fermentation}

The microorganism and the media were expressed in previous study (Jiang et al. 2012). Fermentation experiments were carried out in $250-\mathrm{mL}$ flasks loaded with $50-\mathrm{mL}$ sample solution at $150 \mathrm{rpm}$ and $37^{\circ} \mathrm{C}$ for $60 \mathrm{~h}$. Samples were collected periodically for product concentration analyses. Dry cell weight (DCW) was determined by measuring the absorbance of broth at $600 \mathrm{~nm}\left(\mathrm{OD}_{600}\right)$ using an UV-Vis spectrophotometer (UV1800, Shimadzu) and calculated by the calibrated equation: $\mathrm{DCW}(\mathrm{g} / \mathrm{L})=$ $0.4491 \times \mathrm{OD}_{600}+0.0388\left(\mathrm{R}^{2}=0.984\right)$. The concentration of 2,3-butanediol and acetoin in fermentation broth was determined by HPLC fitted with a refractive index detector and Aminex HPX-87H column at $60^{\circ} \mathrm{C}$ with $0.005 \mathrm{M} \mathrm{H}_{2} \mathrm{SO}_{4}$ as mobile phase at a flow rate of
$0.6 \mathrm{~mL} / \mathrm{min}$. Both 2,3-butanediol and acetoin were considered as the target products in 2,3-butanediol fermentation, and expressed as diol yield:

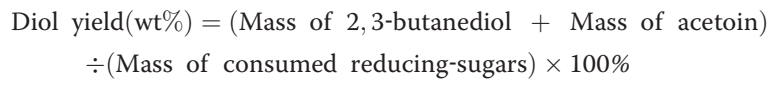

\section{Results}

Biomass recovery and chemical composition before and after pretreatment

The recovery rate of regenerated biomass was determined after IL-pretreatment and collection followed by freeze-drying. It was reported that the recovery rate and chemical composition were affected by sources of biomass, types of ILs, pretreatment time and temperature (Uju et al. 2012). In this work, the recovery rate of ILC was 93.9\%. Jatropha hulls were composed of cellulose, hemicellulose, lignin, long-chain fatty acids, free phenolics and other considerable unknown impurities (Jiang et al. 2012). After washed by water or pretreated by IL, large amount of water- or IL-soluble fraction contained in Jatropha hulls was removed and resulted in low recovery rate of pretreated hulls $(69.7 \%$ for $\mathrm{WJH}$ and $66.7 \%$ for ILJH) and relatively increase of biopolymers (cellulose, hemicellulose and lignin) [from $69.6 \%$ in OJH to $88.1 \%$ in WJH and $91.6 \%$ in ILJH, respectively (Table 1)].

The chemical components and elemental composition of untreated and pretreated Jatropha hulls were analyzed and listed in Table 1 . The content of cellulose in ILJH (48.8\%) was nearly equivalent that in WJH (48.5\%), but the content of hemicellulose in ILJH (12.9\%) was slightly lower than that in WJH (14.6\%). The composition of C, $\mathrm{H}$ and $\mathrm{N}$ in Jatropha hulls changed little (C: 39.2-40.0\%; $\mathrm{H}$ : 5.5-5.9\%; N: 1.1-1.3\%) before and after IL-pretreatment.

Table 1 Chemical and elemental compositions of Jatropha hulls before and after pretreatment

\begin{tabular}{llll}
\hline & OJH (wt\%) & WJH (wt\%) & ILJH (wt\%) \\
\hline Recovery rate: & - & 69.7 & 66.7 \\
Components: & & & \\
Hemicellulose & $12.9 \pm 0.7$ & $14.6 \pm 0.2$ & $12.9 \pm 0.1$ \\
Cellulose & $34.3 \pm 0.6$ & $48.5 \pm 0.4$ & $48.8 \pm 0.4$ \\
Lignin & $22.4 \pm 0.1$ & $25.0 \pm 0.7$ & $29.9 \pm 0.7$ \\
Total & 69.6 & 88.1 & 91.6 \\
Elements: & & & \\
Carbon & 39.2 & 40.0 & 40.0 \\
Hydrogen & 5.5 & 5.0 & 5.9 \\
Nitrogen & 1.1 & 1.0 & 1.3 \\
Total & 45.8 & 46.0 & 47.2 \\
\hline
\end{tabular}




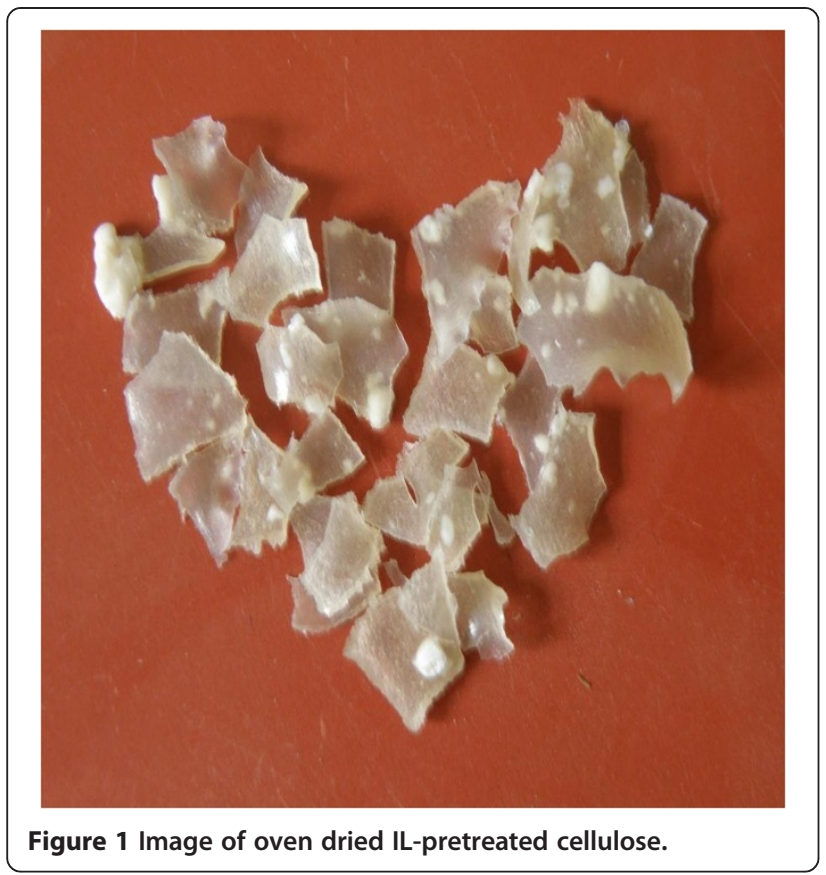

Structural characteristics of the recovered biomass

IL-pretreatment could change the crystalline structure and morphology of cellulose by disrupting inter- and intra-chain hydrogen bonding. In this study, after ILpretreatment and dried in an oven at $70^{\circ} \mathrm{C}$, cellulose became hard plastics-like material (Figure 1) that is hard to be hydrolyzed. Therefore, freeze-drying was used and the structure of biomass became fluffy (Figure 2: b vs. a; $\mathrm{d} v s$. c). The crystallinity and surface area of biomass were evaluated as the most important factors to interpret the structural evolution of biomass after pretreatment. XRD profiles of biomass (Figure 3) showed that untreated cellulose (curve a) has five distinct peaks with their diffraction angles $(2 \theta)$ at around $14.8^{\circ}, 16.3^{\circ}, 20.5^{\circ}$, $22.7^{\circ}$ and $34.5^{\circ}$ that are regarded as characteristics of plane (101), (10 $\overline{1}),(021),(002)$ and (040) of cellulose I (Cheng et al. 2011). However, after IL-pretreatment, the intensity of crystalline peaks at $14.8^{\circ}, 16.3^{\circ}, 22.7^{\circ}$ and $34.5^{\circ}$ decreased remarkably or even disappeared with a flat and broad peak remained at around $20.7^{\circ}$ (curve b). This was due to the reduction in crystalline degree and the transformation of cellulose I to II (Park et al. 2010). In curve c, the intensity of crystalline peaks of cellulose I in WJH decreased. The reason was that amorphous cellulose, and cellulose connected with hemicellulose and lignin in WJH decreased the crystallinity. After ILpretreatment, the intensity of peaks (e.g., 002) dropped further (curve d).

CrI of biomass samples was calculated based on XRD data for quantitative comparison (Table 2). The CrI values of untreated cellulose and WHJ were $95 \%$ and $56 \%$, respectively. After IL-pretreatment, the CrI value decreased
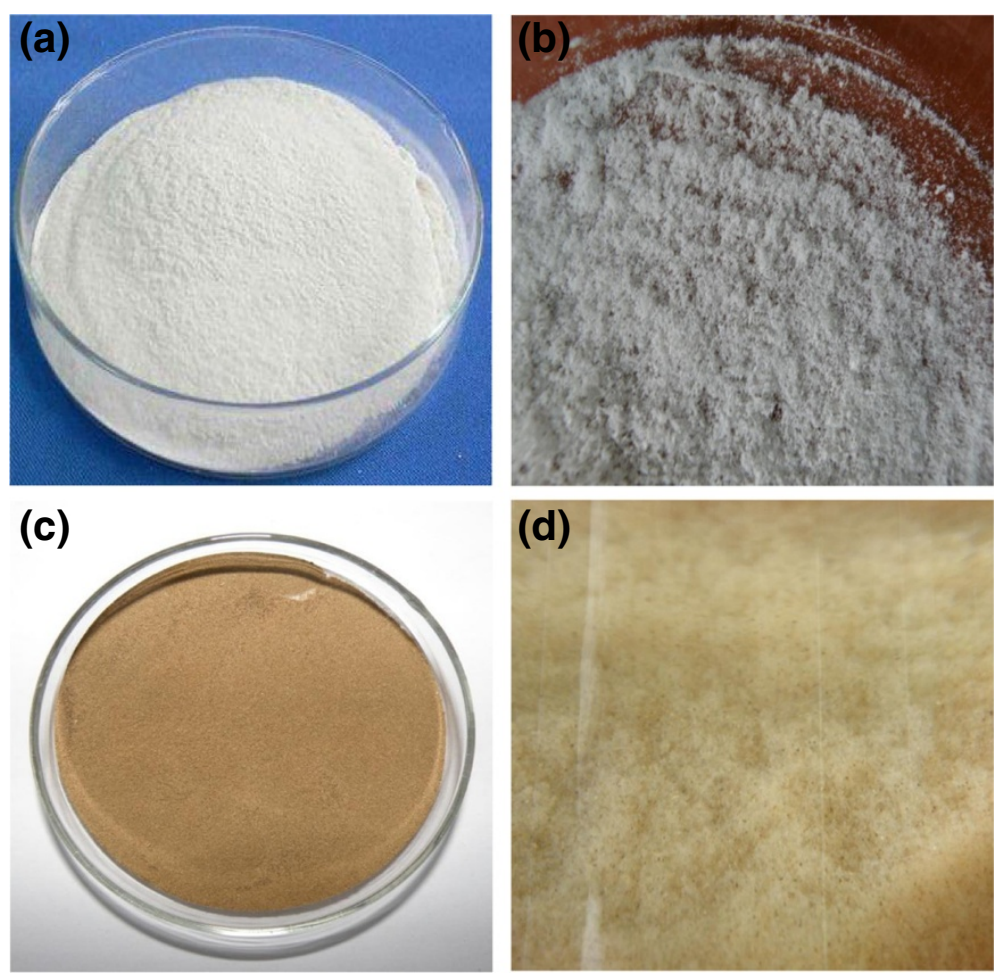

Figure 2 Images of original and freeze-dried pretreated biomass samples. (a) Untreated cellulose; (b) IL-pretreated cellulose; (c) Orginal Jatropha hulls; (d) IL-pretreated Jatropha hulls. 


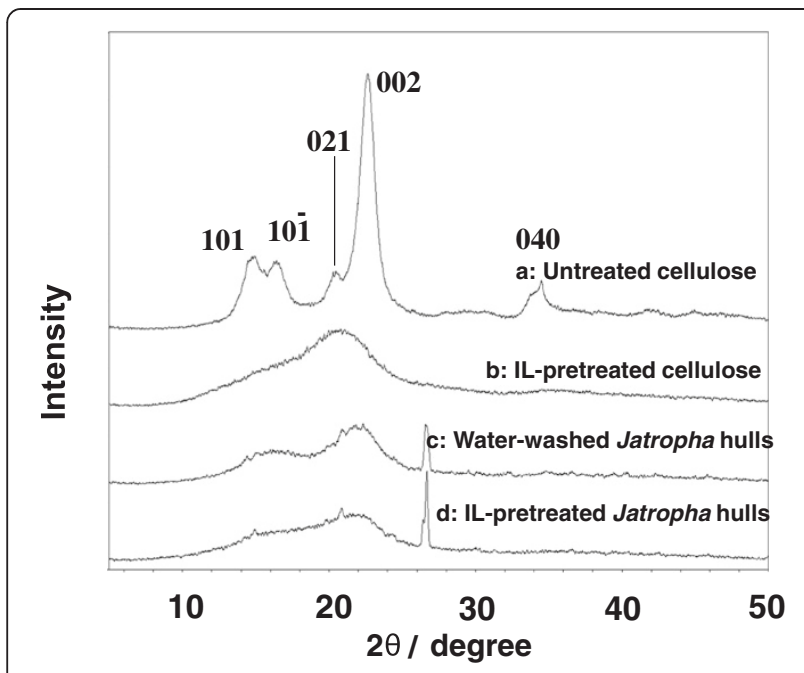

Figure 3 X-ray diffraction (XRD) analysis of biomass samples.

to $18 \%$ for ILC and to $19 \%$ for ILJH, respectively. BET surface area of recovered biomass samples was analyzed and given in Table 2. The surface area of ILC was $3.7 \mathrm{~m}^{2} / \mathrm{g}, 1.54$ times that of untreated cellulose $\left(2.4 \mathrm{~m}^{2} / \mathrm{g}\right)$. Similarly, the surface area of ILJH was $4.4 \mathrm{~m}^{2} / \mathrm{g}, 1.52$ times that of WJH $\left(2.9 \mathrm{~m}^{2} / \mathrm{g}\right)$. The significant decrease in CrI and increase in BET surface area would increase cellulose surface accessibility and theoretically enable more efficient hydrolysis.

\section{Dilute sulfuric acid-hydrolysis}

Based on the previous two-step hydrolysis work on Jatropha hulls (Jiang et al. 2012), the mild first-step optimal conditions $\left(150^{\circ} \mathrm{C}, 1.5 \mathrm{wt} \%\right.$ acid concentration, $0.5 \mathrm{~h}$ ) were selected in this work for the hydrolysis of Jatropha hulls (WJH and ILJH) to avoid secondary decomposition of sugars from hemicellulose. The severe second-step optimal conditions $\left(150^{\circ} \mathrm{C}, 4\right.$ wt $\%$ acid concentration, $1 \mathrm{~h}$ ) were used for the hydrolysis of cellulose (untreated cellulose and ILC). The yields of water-soluble products, reducing-sugars and by-products (5-HMF and furfural) were listed in Table 3. The hydrolysis efficiency of cellulose for sugars production was greatly enhanced after IL-pretreatment. Compared with original cellulose, after IL-pretreatment of cellulose, the yield and concentration of reducing-sugars increased by $139 \%$ (from 33.6 to

Table 2 Crystallinity index and BET surface area of biomass

\begin{tabular}{lll}
\hline Biomass & $\begin{array}{l}\text { Crystallinity index } \\
(\%)\end{array}$ & $\begin{array}{l}\text { BET surface area } \\
\left(\mathbf{~ m}^{\mathbf{2}} / \mathbf{g}\right)\end{array}$ \\
\hline Untreated cellulose & 95 & 2.4 \\
ILC & 18 & 3.7 \\
WJH & 56 & 2.9 \\
ILJH & 19 & 4.4 \\
\hline
\end{tabular}

$80.2 \%$ ) and $139 \%$ (from 15.1 to $36.1 \mathrm{~g} / \mathrm{L}$ ), respectively, and the yield of water-soluble products increased by $128 \%$ (from 39.5 to $90.0 \%$ ) after hydrolysis at $150^{\circ} \mathrm{C}$ with $4 \mathrm{wt} \% \mathrm{H}_{2} \mathrm{SO}_{4}$ for $1 \mathrm{~h}$. More cellulose (15 g) was used to obtain high-concentrated sugars, both yield (from 28.7 to $71.2 \%$ ) and concentration of reducing-sugars (from 21.5 to $53.4 \mathrm{~g} / \mathrm{L}$ ) increased by $148 \%$, and the yield of watersoluble products increased by $128 \%$ (from 34.8 to $79.3 \%$ ). As ILC increased from 9 to $15 \mathrm{~g}$, both the yield of reducing-sugars and yield of water-soluble products decreased to $71.2 \%$ and $79.3 \%$ from $80.2 \%$ and $90.0 \%$, respectively, while the concentration of reducing-sugars increased remarkably (from 36.1 to $53.4 \mathrm{~g} / \mathrm{L}$ ). In the hydrolysis of Jatropha hulls, 15-g samples were used in order to obtain high yield of reducing-sugars. Compared with $\mathrm{WJH}$, for ILJH, the yield and concentration of reducing-sugars increased by $80 \%$ (from 47.6 to $85.7 \%$ ) and $76 \%$ (from 22.6 to $39.7 \mathrm{~g} / \mathrm{L}$ ), respectively, and the yield of water-soluble products increased by $70 \%$ (from 35.5 to $60.2 \%$ ) after hydrolysis at $150^{\circ} \mathrm{C}$ with 1.5 wt\% $\mathrm{H}_{2} \mathrm{SO}_{4}$ for $0.5 \mathrm{~h}$. The yield of water-soluble products for Jatropha hulls was lower than that for cellulose due to its content of lignin (Eq. 4).

Furfural and 5-HMF were inhibitors in fermentation, while their formation also meant the loss of fermentable sugars. So, furfural and 5-HMF should be avoided. In this work, the increase of the total yield of furfurals (5-HMF and furfural) after IL-pretreatment meant more secondary degradation (from $2.1 \%$ for $\mathrm{WJH}$ to $3.0 \%$ for ILJH). The by-products can be reduced by using more moderate reaction conditions (such as, lower $\mathrm{H}_{2} \mathrm{SO}_{4}$ concentration, shorter reaction time and lower temperature).

\section{Fermentation}

After distilled condensation and detoxification by charcoal adsorption, furfural and 5-HMF were removed. The hydrolysates (76.91-81.15 g/L reducing-sugars) were fermented for 2,3-butanediol production, with results given in Figures 4 and 5, and Table 4. In Figure 4a, the fermentation of hydrolysates from untreated cellulose was undertaken with initial reducing-sugars concentration of $80.65 \mathrm{~g} / \mathrm{L}$ in flasks. After $60 \mathrm{~h}, 5.76 \mathrm{~g} / \mathrm{L} \mathrm{DCW}$ and $32.41 \mathrm{~g} / \mathrm{L}$ diol were achieved, giving diol productivity of $0.54 \mathrm{~g} /(\mathrm{L} \cdot \mathrm{h}$ ) and yield of $40.61 \%$ (equivalent to $81.22 \%$ of the theoretical value). In Figure $4 \mathrm{~b}$, ILC hydrolysate $(81.15 \mathrm{~g} / \mathrm{L})$ achieved $5.93 \mathrm{~g} / \mathrm{L}$ DCW and $33.49 \mathrm{~g} / \mathrm{L}$ diol, with diol yield of $41.60 \%$ (equivalent to $83.20 \%$ of the theoretical value) and diol productivity of $0.56 \mathrm{~g} /(\mathrm{L} \cdot \mathrm{h})$. It was clearly demonstrated that diol yield and productivity from ILC hydrolysate were close to those from untreated cellulose hydrolysate because their hydrolysates had similar components. The hydrolysates from celluloses with and without pretreatment after detoxification were free of the contaminants that inhibited 
Table 3 The yields of water-soluble products, reducing-sugars, 5-HMF and furfural as well as concentration of reducing-sugars

\begin{tabular}{llllll}
\hline Biomass* & $\begin{array}{l}\text { Yield of reducing-sugars } \\
(\%)^{* *}\end{array}$ & $\begin{array}{l}\text { Concentration of } \\
\text { reducing-sugars (g/L) }\end{array}$ & $\begin{array}{l}\text { Yield of water-soluble } \\
\text { products (\%) }\end{array}$ & $\begin{array}{l}\text { Yield of 5-HMF } \\
(\%)^{* *}\end{array}$ & $\begin{array}{l}\text { Yield of furfural } \\
\text { (\%)** }\end{array}$ \\
\hline C-9 & 33.6 & 15.1 & 39.5 & 0.4 & 0.1 \\
C-15 & 28.7 & 21.5 & 34.8 & 0.4 & 0.1 \\
ILC-9 & 80.2 & 36.1 & 90.0 & 1.3 & 1.5 \\
ILC-15 & 71.2 & 53.4 & 79.3 & 0.7 & 0.7 \\
WJH-15 & 47.6 & 22.6 & 35.5 & 0.4 & 1.7 \\
ILH-15 & 85.7 & 39.7 & 60.2 & 0.6 & 2.4 \\
\hline
\end{tabular}

Hydrolysis conditions: $200 \mathrm{~mL} 4 \mathrm{wt} \% \mathrm{H}_{2} \mathrm{SO}_{4}, 150^{\circ} \mathrm{C}, 1 \mathrm{~h}$ for cellulose; $200 \mathrm{~mL} 1.5 \mathrm{wt} \% \mathrm{H}_{2} \mathrm{SO}_{4}, 150^{\circ} \mathrm{C}, 0.5 \mathrm{~h}$ for Jatropha hulls.

${ }^{*} \mathrm{C}-9$ : 9 g untreated cellulose;

C-15: $15 \mathrm{~g}$ untreated cellulose;

ILC-9: $9 \mathrm{~g}$ ionic liquid pretreated cellulose;

ILC-15: $15 \mathrm{~g}$ ionic liquid pretreated cellulose;

WJH-15: $15 \mathrm{~g}$ water-washed Jatropha hulls;

ILJH-15: $15 \mathrm{~g}$ IL-pretreated Jatropha hulls.

** Data (\%) were based on total mass of cellulose and hemicellulose in substrates.

microbial growth and metabolic pathway for 2,3butanediol production.

Figure 5 showed fermentation results of hydrolysates from WJH and ILJH in flasks, with initial reducingsugars concentrations of $77.41 \mathrm{~g} / \mathrm{L}$ and $76.91 \mathrm{~g} / \mathrm{L}$, respectively. For the fermentation of WJH hydrolysate, $3.58 \mathrm{~g} / \mathrm{L}$ DCW and $20.70 \mathrm{~g} / \mathrm{L}$ diol were produced after $60 \mathrm{~h}$, giving diol yield of $28.60 \%$ (equivalent to $57.20 \%$ of the theoretical value) and diol productivity of $0.35 \mathrm{~g} /(\mathrm{L} \cdot \mathrm{h})$. For the fermentation of ILJH hydrolysate, products contained $4.61 \mathrm{~g} / \mathrm{L} \mathrm{DCW}$ and $24.13 \mathrm{~g} / \mathrm{L}$ diol, with diol yield of $33.29 \%$ (equivalent to $66.58 \%$ of the theoretical value) and diol productivity of $0.40 \mathrm{~g} /(\mathrm{L} \cdot \mathrm{h})$, which were higher than those of WJH hydrolysate.

\section{Discussion}

In the case of bulk chemicals and biofuels, the cost of the raw material mostly affected the price of the final products. The efficient utilization of biomass was essential for the economical production of 2,3-butanediol. In the previous two-step dilute sulfuric acid hydrolysis of Jatropha hulls, total water-soluble products yield was $64 \%$, which was higher than that (37\%) from the first- step hydrolysis (Jiang et al. 2012). In this work, the yield of water-soluble products of ILJH reached similar total value $(60.2 \%)$ by just using the first-step hydrolysis conditions. The yield of water-soluble products for ILJH was greatly enhanced $(60.2 \%$ vs. $37 \%)$. In the combination of IL-pretreatment and enzyme hydrolysis of cellulose (Tian et al. 2011), glucose yield was 59\% after $72 \mathrm{~h}$ hydrolysis time as compared with $80.2 \%$ yield of reducing-sugars for ILC in this work. Therefore, this hydrolysis work reached relatively high yield of watersoluble products for IL-pretreated biomass samples under milder conditions.

Separation of 2,3-butanediol from fermentation media is one of economic barriers for the commercial production of microbial 2,3-butanediol (Ji et al. 2011). High concentration of 2,3-butanediol can cut the cost of downstream separation. So, high concentration of initial fermentable sugars is required for practical applications. In the previous study, for example, concentration of glucose $(200 \mathrm{~g} / \mathrm{L})$ was used and relative high concentration of 2,3-butanediol (95.5 g/L) was achieved (Ji et al. 2009). However, the concentration of total reducing-sugars obtained from lignocellulose hydrolysates was about
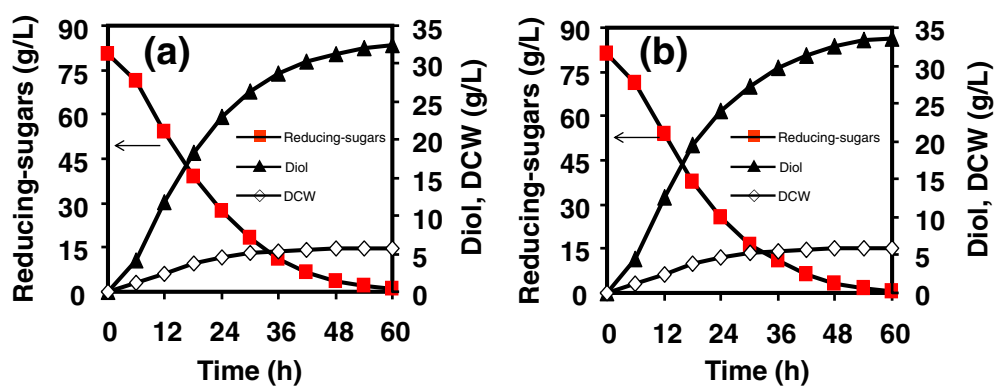

Figure 4 2,3-Butanediol fermentation by Klebsiella oxytoca for $60 \mathrm{~h}$ using cellulose hydrolysate as substrate in flasks. (a) hydrolysate from cellulose, (b) hydrolysate from IL-pretreated cellulose. 

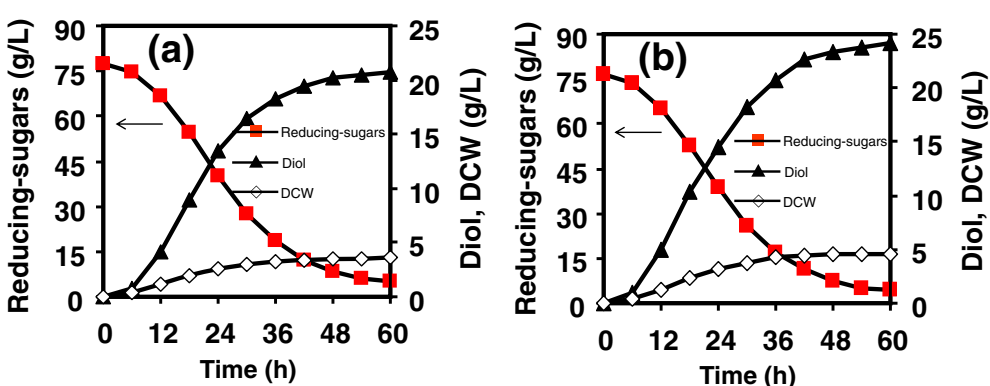

Figure 5 2,3-Butanediol fermentation by Klebsiella oxytoca for $60 \mathrm{~h}$ using Jatropha hulls hydrolysate as substrate in flasks. (a) hydrolysate from water-washed Jatropha hulls, (b) hydrolysate from IL-pretreated Jatropha hulls.

20-30 g/L (Guo et al. 2008; Cheng et al. 2010; Jiang et al. 2012). So, increasing the reducing-sugars concentration in lignocellulose hydrolysates is one of the key problems for the high efficient production of biomass-derived 2,3butanediol. In this work, after IL-pretreatment, the concentration of reducing-sugars increased to $53.4 \mathrm{~g} / \mathrm{L}$ from $21.5 \mathrm{~g} / \mathrm{L}$ for cellulose, and the concentration of reducing-sugars increased to $39.7 \mathrm{~g} / \mathrm{L}$ from 22.6 for lignocellulose.

In the previous work (Table 4), some chemicals after hydrolysis had significantly unfavorable influence on the 2,3-butanediol metabolic pathway and biological activities (Jiang et al. 2012). After fermentation of OJH hydrolysate (obtained from the first-step hydrolysis) for $60 \mathrm{~h}$, only $5.5 \%$ diol yield was achieved. However, after washed with neutral detergent to remove extractives (e.g., proteins, lipids, pectins and nonfibrous carbohydrates) and twostep hydrolysis, diol yields reached $35.6 \%$ and $41.4 \%$ from the hydrolysates of the first- and second-step hydrolysis, respectively. Compared with $\mathrm{OJH}$ hydrolysate, the fermentation efficiency of $\mathrm{WJH}$ and $\mathrm{ILJH}$ hydrolysates were much higher. The reason was that most of fermentation inhibitors produced from the extractives during hydrolysis of $\mathrm{OJH}$ were removed by water-washed and
IL-pretreatment. IL-pretreatment benefited the fermentation of Jatropha hulls hydrolysate more than waterwashed pretreatment might due to the more effective removal of extractives. On the other hand, the yields of diol from WJH (28.60\%) and ILJH (33.29\%) hydrolysates in this work were slightly lower than that from the first-step hydrolysate from neutral detergent pretreated Jatropha hulls (35.6\%) due to minor extractives still remaining in WJH and ILJH. Glucose had higher efficiency for fermentation than other sugars (Wang et al. 2010). Therefore, the diol yield from the cellulose hydrolysate solution (41.6\%) was higher than that from the hydrolysate of ILJH (33.29\%), and was close to that of second-step hydrolysate (41.4\%) from the solid residue (mainly cellulose) of the first-step hydrolysis of Jatropha hulls. Corncob acid hydrolysates were used as feedstocks for fermentation and after $60 \mathrm{~h}$ of fed-batch fermentation, a maximal $35.7 \mathrm{~g} / \mathrm{L}$ 2,3-butanediol was obtained, giving a productivity of $0.59 \mathrm{~g} /(\mathrm{L} \cdot \mathrm{h})$ and a highest diol yield of $50 \%$ reported so far (Cheng et al. 2010). In the work of Grover et al. (1990), wood acid hydrolysate neutralized with $\mathrm{Ca}(\mathrm{OH})_{2}$ had been used for 2,3-butanediol production, obtaining $13.3 \mathrm{~g} / \mathrm{L} \mathrm{2,3-butanediol} \mathrm{with} \mathrm{a} \mathrm{yield} \mathrm{of}$ $29 \%$ and a productivity of $0.28 \mathrm{~g} / \mathrm{L} \mathrm{h}$.

Table 4 2,3-Butanediol fermentation by Klebsiella oxytoca for $60 \mathrm{~h}$ using different substrates in flasks

\begin{tabular}{|c|c|c|c|c|}
\hline \multirow[t]{2}{*}{ Substrates } & \multicolumn{3}{|c|}{ Diol (2,3-butanediol + acetoin) } & \multirow[t]{2}{*}{ References } \\
\hline & Concentration $\mathrm{g} / \mathrm{L}$ & Productivity $g /(L \cdot h)$ & Yield* \% & \\
\hline Hydrolysate from cellulose & 32.41 & 0.54 & $40.61(81.22)$ & This study \\
\hline Hydrolysate from ILC & 33.49 & 0.56 & $41.60(83.20)$ & This study \\
\hline Hydrolysate from WJH & 20.70 & 0.35 & $28.60(57.20)$ & This study \\
\hline Hydrolysate from ILH & 24.13 & 0.40 & $33.29(66.58)$ & This study \\
\hline Original Jatropha hulls hydrolysate from the first-step hydrolysis & 4.11 & 0.069 & $5.50(11)$ & Jiang et al. (2012) \\
\hline First-step hydrolysate from pretreated Jatropha hulls & 25.03 & 0.42 & $35.6(71.2)$ & Jiang et al. (2012) \\
\hline Second-step hydrolysate from the solid residue of the first step & 31.57 & 0.53 & $41.4(82.8)$ & Jiang et al. (2012) \\
\hline Glucose & 97.4 & 1.74 & $49.0(98.0)$ & Ji et al. (2009) \\
\hline Corncob acid hydrolysate & 35.7 & 0.59 & $50.0(100.0)$ & Cheng et al. (2010) \\
\hline Wood acid hydrolysate & 13.3 & 0.28 & $29.0(58.0)$ & Grover et al. (1990) \\
\hline
\end{tabular}

*The data in brackets were equivalent of theoretical values. 
In conclusion, in this study, IL-pretreatment and dilute acid-hydrolysis were performed to produce fermentable sugars from cellulose and Jatropha hulls. The yield of water-soluble products increased to $90.0 \%$ for IL-pretreated cellulose from $39.5 \%$ for original cellulose. For Jatropha hulls, after IL-pretreatment, the yield of water-soluble products rose to $60.2 \%$ from $35.5 \%$ for water-washed Jatropha hulls. IL-pretreatment also benefited the fermentation of Jatropha hulls hydrolysate due to the removal of extractives, with diol productivity increased to 0.40 from $0.35 \mathrm{~g} /(\mathrm{L} \cdot \mathrm{h})$ for water-washed Jatropha hulls. The techniques developed in this paper may be applied to other similar industrial microorganisms for the production of biofuels from biomass wastes.

\section{Competing interests}

The authors declare that they have no competing interests.

\section{Authors' contributions}

LQJ and ZF (supervisor) conceived the study. LQJ carried out pretreatment, hydrolysis and fermentation experiments, and drafted manuscript. ZF and JL participated in test design and supervision, and revised the manuscript. XKL participated in the preparation of material and hydrolysis experiments and $J \mathrm{~L}$ participated in the statistics analysis. All authors read and approved the final manuscript.

\section{Acknowledgements}

This work was supported by the Chinese Academy of Sciences [100 talents program, CAS 135 program (XTBG-T02) and equipment R\&D grant (No.YZ201260)] Yunnan 100 overseas talents program and the Natural Science Foundation of China (No. 21076220).

\section{Author details}

${ }^{1}$ Biomass Group, Laboratory of Tropical Plant Resource Science, Xishuangbanna Tropical Botanical Garden, Chinese Academy of Sciences, 88 Xuefulu, Kunming Yunnan Province 650223, China. ${ }^{2}$ University of Chinese Academy of Sciences, $19 \mathrm{~A}$ Yuquan Road, Beijing 100049, China.

Received: 13 August 2013 Accepted: 14 August 2013

Published: 20 August 2013

\section{References}

Binder JB, Raines RT (2010) Fermentable sugars by chemical hydrolysis of biomass. PNAS 107:4516-4521

Celińska E, Grajek W (2009) Biotechnological production of 2,3-butanediol-current state and prospects. Biotechnol Adv 27:715-725

Cheng KK, Liu Q, Zhang JA, Li JP, Xu JM, Wang GH (2010) Improved 2,3-butanediol production from corncob acid hydrolysate by fed-batch fermentation using Klebsiella oxytoca. Process Biochem 45:613-616

Cheng G, Varanasi P, Li CL, Liu HB, Menichenko YB, Simmons BA, Kent MS, Singh S (2011) Transition of cellulose crystalline structure and surface morphology of biomass as a function of ionic liquid pretreatment and its relation to enzymatic hydrolysis. Biomacromolecules 12:933-941

Garg SK, Jain A (1995) Fermentative production of 2,3-butanediol: a review. Bioresour Technol 51:103-109

Grover BP, Garg SK, Verma J (1990) Production of 2,3-butanediol from wood hydrolysate by Klebsiella pneumoniae. World J Microbiol Biotechnol 6:328-332

Guo GL, Chen WH, Chen HW, Men LC, Hwang WS (2008) Characterization of dilute acid pretreatment of silvergrass for ethanol production. Bioresour Technol 99:6046-6053

Ji XJ, Huang H, Du J, Zhu JG, Ren LJ, Hu N, Li S (2009) Enhanced 2,3-butanediol production by Klebsiella oxytoca using a two-stage agitation speed control strategy. Bioresour Technol 100:3410-3414

Ji XJ, Huang H, Ouyang PK (2011) Microbial 2,3-butanediol production: A state-of -the-art review. Biotechnol Adv 29:351-364
Jiang LQ, Fang Z, Guo F, Yang LB (2012) Production of 2,3-butanediol from acid hydrolysates of Jatropha hulls with Klebsiella oxytoca. Bioresour Technol 107:405-410

Li CL, Sun L, Simmons BA, Singh S (2013) Comparing the recalcitrance of eucalyptus, pine, and switchgrass using ionic liquid and dilute acid pretreatments. Bioenerg Res 6:14-23

Liu CZ, Wang F, Stiles AR, Guo C (2012) lonic liquids for biofuel production: Opportunities and challenges. Appl Energy 92:406-414

Marasabessy A, Kootstra AMJ, Sanders JPM, Weusthuis RA (2012) Dilute $\mathrm{H}_{2} \mathrm{SO}_{4}$-catalyzed hydrothermal pretreatment to enhance enzymatic digestibility of Jatropha curcas fruit hull for ethanol fermentation. Int J Energy Environ Eng 3:15

Miller GL (1959) Use of dinitrosalicylic acid reagent for determination of reducing sugar. Anal Chem 31:426-428

Park S, Baker JO, Himmel ME, Parilla PA, Johnson DK (2010) Cellulose crystallinity index:measurement techniques and their impact on interpreting cellulase performance. Biotechnol Biofuels 3:10

Segal L, Creely JJ, Martin AE Jr, Conrad CM (1959) An empirical method for estimating the degree of crystallinity of native cellulose using the X-ray diffractometer. Text Res J 29:786-794

Shafiei M, Zilouei H, Zamani TMJ, Karimi K (2013) Enhancement of ethanol production from spruce wood chips by ionic liquid pretreatment. Appl Energy 102:163-169

Sharma DK, Pandey AK, Lata (2009) Use of Jatropha curcas hull biomass for bioactive compost production. Biomass Bioenergy 33:159-162

Sluiter A, Hames B, Ruiz R, Scarlata C, Sluiter J, Templeton D, Crocker D (2008) Determination of structural carbohydrates and lignin in biomass. Laboratory Analytical Procedure. NREL, Golden Colorado

Syu MJ (2001) Biological production of 2,3-butanediol. Appl Microbiol Biotechnol 55:10-18

Tian XF, Fang Z, Jiang D, Sun XY (2011) Pretreatment of microcrystalline cellulose in organic electrolyte solutions for enzymatic hydrolysis. Biotechnol Biofuels 4:53

Uju SY, Nakamoto A, Goto M, Tokuhara W, Noritake Y, Katahira S, Ishida N, Nakashima K, Ogino C, Kamiya N (2012) Short time ionic liquids pretreatment on lignocellulosic biomass to enhance enzymatic saccharification. Bioresour Technol 103:446-452

Wang AL, Wang Y, Jiang TY, Li LX, Ma CQ, Xu P (2010) Production of 2,3-butanediol from corncob molasses, a waste by-product in xylitol production. Appl Microbiol Biotechnol 87:965-970

doi:10.1186/2191-0855-3-48

Cite this article as: Jiang et al:: Production of 2,3-butanediol from cellulose and Jatropha hulls after ionic liquid pretreatment and diluteacid hydrolysis. AMB Express 2013 3:48.

\section{Submit your manuscript to a SpringerOpen ${ }^{\circ}$ journal and benefit from:}

- Convenient online submission

- Rigorous peer review

- Immediate publication on acceptance

- Open access: articles freely available online

- High visibility within the field

- Retaining the copyright to your article

Submit your next manuscript at $>$ springeropen.com 